\title{
Diagnostic Accuracy of MR-Spectroscopy in Diagnosis of Focal Liver Malignant Lesions Taking Histopathology as Gold Standard
}

\author{
Nosheen Ahmad, Sehrish Israr, Sumaira Irshad, Irfan Shabbir, Amna Rehan, Hassan Bukhari
}

\begin{abstract}
Objective: To determine the diagnostic accuracy of MR-spectroscopy in diagnosis of focal liver malignant lesions taking histopathology as gold standard. Study Design: Cross-Sectional Validation Study. Settings: The study was conducted in Radiology Department of Allied Hospital Faisalabad. Duration: Six months from 1st October 2017 to 31st March 2018. Methodology: Permission for research was sought from hospital ethical committee. Patients were collected from OPD \& indoor departments of Radiology and Medicine of Allied Hospital Faisalabad. Objective of study was explained to every subject who fulfilled the inclusion criteria and informed consent was taken. Confounding variables were controlled by restriction (by excluding subjects with history of metastatic disease and chemotherapy). MRS examination was performed with the patients in supine position using 1.5-T Philips MRI unit and a body phased array coil. This procedure was performed in Radiology Department Allied Hospital Faisalabad. Biopsy was taken from the patients and histopathology was done from histopathology lab PMC/Allied Hospital Faisalabad. Finally, the data was collected. Results: In this study, diagnostic accuracy of MR-spectroscopy in diagnosis of focal liver malignant lesions taking histopathology as gold standard was calculated as $93.75 \%$ for sensitivity, $90.20 \%$ for specificity, $92.31 \%$ for positive predictive value, $92.00 \%$ for negative predictive value and $92.17 \%$ for accuracy rate, positive likelihood ratio was 9.56 and negative likelihood ratio was 0.07 . Conclusion: It is concluded that the diagnostic accuracy of MR-spectroscopy is comparable and is better as it is less invasive in diagnosing of focal liver malignant lesions taking histopathology as gold standard. However, these findings are primary and needs validation through some other local studies.
\end{abstract}

Keywords: Focal liver malignant lesions, Diagnosis, MR-spectroscopy, Diagnostic accuracy.

Corresponding Author

Submitted for Publication: 13-01-2020

Accepted for Publication: 21-01-2020

DR. NOSHEEN AHMAD, Assistant Professor of Radiology, Faisalabad Medical University, Allied Hospital, Faisalabad-Pakistan.

Contact / Email: +92 300-6652174, drnosheenahmad@hotmail.com

Citation: Ahmad N, Israr S, Irshad S, Shabbir I, Rehan A, Bukhari H. Diagnostic Accuracy of MR-Spectroscopy in Diagnosis of Focal Liver Malignant

Lesions Taking Histopathology as Gold Standard. APMC 2020;14(1):87-91.

\section{INTRODUCTION}

Primary liver cancer is the fifth most common malignancy in men and eighth in women worldwide. The liver is also the second most common site for metastatic spread of cancer. In fact, liver lesions are more likely to represent a metastatic tumor than a primary liver tumor. ${ }^{1}$

Currently tissue sample analysis by histopathology is gold standard for the diagnosis of suspected liver lesions. However, taking biopsies for histopathological analysis has some disadvantages. Besides patient discomfort, there is a chance that needle misses the cancer foci. Also, the needle might loosen cancerous cells which could result in tumor dissemination outside the liver along the needle track. ${ }^{1}$

To assist in the diagnosis of liver lesions, noninvasive advanced imaging techniques are desireable. ${ }^{1}$ More importantly the evaluation of liver lesions need a detailed history, physical examination and radiological tests. For example, history of oral contraceptive use in the absence of underlying liver disease suggests the diagnosis of hepatocellular adenoma, whereas a focal liver lesion in the setting of chronic liver disease and portal hypertension should lead to high suspicion of diagnosis of hepatocellular carcinoma. ${ }^{2}$

Among noninvasive imaging techniques, The MR technique is very versatile and it offers many possibilities to acquire more functional information. Among these MR-spectroscopy (MRS) is particularly interesting. ${ }^{1}$ It differs from conventional MRI in that the spectra provides physiological and chemical information instead of anatomy. MRS has also been used for treatment monitoring and patient follow up. ${ }^{6}$

MR-spectroscopy can be used to measure hepatic metabolite levels in patients with liver cirrhosis and to predict the probability of patient progression to develop hepatocellular carcinoma. ${ }^{3}$ Choline is one of the components of the cell membrane with phospholipid metabolism and is an effective indicator of cell proliferation. In normal liver tissues and benign tumors choline levels are low, but choline levels are high in malignancy. ${ }^{4}$

In addition, lipid metabolism largely depends on normal liver function. Abnormal lipid metabolism seen in fatty liver but it is also a marker of membrane breakdown and can be seen in tumor, abscess and other pathological processes. ${ }^{5}$

In view of recently reported concerns, MR-spectroscopy is helpful in evaluation of focal hepatic lesions. The sensitivity of MRS in differentiating cirrhotic liver tissue and HCC is $95.8 \%$ and specificity is $88.9 \%$ keeping histopathology as gold standard which shows high specificity $(98-100 \%)$ and high sensitivity (86-100\%) for the diagnosis of malignancy. ${ }^{1}$

This study would assess the usefulness of MR-spectroscopy in differentiating focal liver lesions according to histology and would be helpful for both the patients as well as doctors by using non-invasive method (MR-Spectroscopy).This will also guide and help the physician and oncologist in their treatment plans and will avoid the patients fear and complications of interventional procedure. 


\section{METHODOLOGY}

Study Design: Cross-Sectional Study.

Settings: Department of Radiology and Medicine of Allied Hospital Faisalabad Pakistan.

Duration: Six months from 1 st October 2017 to 31 $1^{\text {st }}$ March 2018. Sample Technique: Non probability consecutive sampling.

Sample Size: 115 cases.

Inclusion Criteria: Patients between 15 to 65 years of age of both genders and who had suspected hepatic lesions (not less than $3 \mathrm{~cm}$ in diameter) with no evidence of metastatic disease on abdominal USG were taken.

Exclusion Criteria: Patients with diffuse type HCC, with focal nodular hyperplasia, obvious fatty infiltration and histological unconfirmed lesions were not included and those patients who are currently undergoing chemotherapy and with history of any trauma or surgery which may have left ferromagnetic material in the body, ferromagnetic implants and pacemakers were excluded from the study.

Methods: Permission for research was taken from hospital ethical committee. Consecutive patients were collected from OPD \& indoor departments of Radiology and Medicine of Allied Hospital Faisalabad. And informed written consent was taken. MRS examination was performed with the patients in supine position using 1.5-T Philips MRI unit and a body phased array coil.

MRS examination performed in fasting at least 8h, and using segmented breath-hold method. Single voxel PRESS with TE= $30 \mathrm{~ms}, \mathrm{TR}=1500 \mathrm{~ms}, 256$ averages, were used to select a volume of $2 \mathrm{~cm}^{\star} 2 \mathrm{~cm} * 3 \mathrm{~cm}$. The voxel of interest was located in largest solid portion of hepatic tumors in patients. A Region of interest (ROI size is $2 * 2 \mathrm{~cm} 2$ ) was drawn in T2W images to target the raw MR spectrum images. Data was analyzed using LC Model software to generate data on the level of choline and lipid in the liver as well as the ( $\mathrm{c} \mathrm{h} \mathrm{o/lipid).} \mathrm{Lesion} \mathrm{is} \mathrm{said} \mathrm{to} \mathrm{be} \mathrm{benign}$ if there is reduction in choline to lipid ratio (cho/lipid) on MRSpectroscopy. Lesion is said to be malignant if choline to lipid ratio (cho/lipid) is higher on MR-Spectroscopy.

MR-Spectroscopy criteria include choline to lipid ratio (c $\mathrm{h}$ ol lipid). The choline to lipid ratio is measured (cho/lipid) by dividing the peak area of choline at 3.2ppm by the peak area of lipid at 1.3ppm. Malignant tumors have high choline to lipid resonances compared to benign tumors with an optimal cut-off (cho/lipid) value of $0.1 \mathrm{ppm}$.

This procedure was performed in Radiology Department Allied Hospital Faisalabad. Biopsy was taken from the patients and histopathology was done from histopathology lab PMC/Allied Hospital. Finally, the data was collected.

Data was analyzed by using SPSS V-2. Descriptive statistics were calculated for all variables. Mean and standard deviation was calculated for all quantitative variables like age, frequency and percentage was calculated for qualitative variable like true positive and gender. Sensitivity, Specificity, PPV, NPV and diagnostic accuracy was calculated by constructing $2^{\star} 2$ table by taking histopathology as gold standard.

Likelihood ratio was calculated. Effect modifiers like age and gender was controlled by stratification. Post stratification diagnostic accuracy was applied. P-value $<0.05$ was taken as significant.

\section{RESULTS}

A total of 115 cases fulfilling the inclusion/exclusion criteria were enrolled to determine the diagnostic accuracy of MRspectroscopy in diagnosis of focal liver malignant lesions taking histopathology as gold standard.

Age distribution of the patients was done, it shows that $24.35 \%(n=28)$ were between $15-40$ years of age whereas $75.65 \%(n=87)$ were between $41-65$ years of age, mean \pm SD was calculated as $36.77 \pm 12.98$ years. (Table No. 1 )

Table 1: Age distribution $(n=115)$

\begin{tabular}{|c|c|c|}
\hline Age (in years) & No. of patients & $\%$ \\
\hline $15-40$ & 28 & 24.35 \\
\hline $41-65$ & 87 & 75.65 \\
\hline Total & 115 & 100 \\
\hline Mean \pm SD & $36.77 \pm 12.98$ \\
\hline
\end{tabular}

Gender distribution shows that $53.91 \%(n=62)$ were male and $46.09 \%(n=53)$ were females. (Table No. 2$)$

Table 2: Gender distribution $(n=115)$

\begin{tabular}{|c|c|c|}
\hline Gender & No. of patients & $\%$ \\
\hline Male & 62 & 53.91 \\
\hline Female & 53 & 46.09 \\
\hline Total & 115 & 100 \\
\hline
\end{tabular}

Frequency of focal liver malignant lesions on histopathology as gold standard was calculated as $55.65 \%(n=64)$ whereas $44.35 \%(n=51)$ had no findings of the morbidity. (Figure 1$)$

\section{Focal Liver Malignant Lesions}

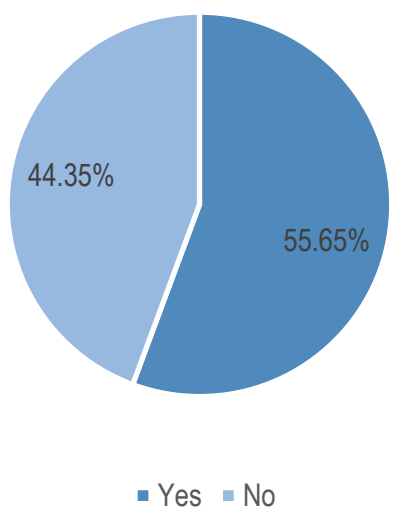

Figure 1: Frequency of focal liver malignant lesions on histopathology as gold standard $(n=115)$ 
Diagnostic accuracy of MR-spectroscopy in diagnosis of focal liver malignant lesions taking histopathology as gold standard was calculated as $93.75 \%$ for sensitivity, $90.20 \%$ for specificity, $92.31 \%$ for positive predictive value, $92.00 \%$ for negative predictive value and $92.17 \%$ for accuracy rate, positive likelihood ratio was 9.56 and negative likelihood ratio was 0.07 . (Table No. 3)

Table 3: Diagnostic accuracy of MR-Spectroscopy in diagnosis of focal liver malignant lesions taking histopathology as gold standard $(n=115)$

\begin{tabular}{|c|c|c|c|}
\hline \multirow{4}{*}{ MRS } & \multicolumn{2}{|c|}{ Histopathology } & \multirow{2}{*}{ Total } \\
\cline { 2 - 4 } & $\begin{array}{c}\text { Focal Liver } \\
\text { Malignant Lesions }\end{array}$ & $\begin{array}{c}\text { Focal Liver } \\
\text { Malignant Lesions }\end{array}$ & \\
& (Positive) & (Negative) & \\
\hline \multirow{2}{*}{ Positive } & True positive(a) & False positive (b) & $\mathrm{a}+\mathrm{b}$ \\
& 60 & 5 & 48 \\
\hline \multirow{2}{*}{ Negative } & False negative(c) & True negative (d) & $\mathrm{c}+\mathrm{d}$ \\
& 4 & 46 & 54 \\
\hline
\end{tabular}

Sensitivity $\quad=a /(a+c) \times 100=93.75 \%$

Specificity $\quad=d /(d+b) \times 100=90.20 \%$

Positive predictive value $=a /(a+b) \times 100=92.31 \%$

Negative predictive value $=d /(d+c) \times 100=92.00 \%$

Accuracy rate $=a+d /(a+d+b+c) \times 100=92.17 \%$

Positive Likelihood Ratio: 9.56

Negative Likelihood Ratio: 0.07

Effect modifiers like age and gender was controlled by stratification. Post stratification diagnostic accuracy was applied. P-value $\leq 0.05$ was taken as significant. (Table No. 4-5)

Table 4: Diagnostic accuracy of MR-Spectroscopy in diagnosis of focal liver malignant lesions taking histopathology as gold standard with regards to age

Age: $15-40$ years

\begin{tabular}{|c|c|c|c|}
\hline \multirow[b]{2}{*}{ MRS } & \multicolumn{2}{|c|}{ Histopathology } & \multirow[b]{2}{*}{$\begin{array}{c}P \\
\text { value }\end{array}$} \\
\hline & $\begin{array}{c}\text { Focal Liver } \\
\text { Malignant Lesions } \\
\text { (Positive) }\end{array}$ & $\begin{array}{c}\text { Focal Liver } \\
\text { Malignant Lesions } \\
\text { (Negative) }\end{array}$ & \\
\hline Positive & $\begin{array}{l}\text { True positive(a) } \\
20\end{array}$ & $\begin{array}{c}\text { False positive (b) } \\
1\end{array}$ & \multirow[b]{2}{*}{0.000} \\
\hline Negative & $\begin{array}{c}\text { False negative(c) } \\
1\end{array}$ & $\begin{array}{l}\text { True negative (d) } \\
6\end{array}$ & \\
\hline
\end{tabular}

Sensitivity $\quad=a /(a+c) \times 100=95.24 \%$

Specificity $\quad=d /(d+b) \times 100=85.71 \%$

Positive predictive value $=a /(a+b) \times 100=95.24 \%$

Negative predictive value $=d /(d+c) \times 100=85.71 \%$

Accuracy rate $=a+d /(a+d+b+c) \times 100=92.86 \%$

Positive Likelihood Ratio: 6.67

Negative Likelihood Ratio: 0.06
Age: 41-65 years

\begin{tabular}{|c|c|c|c|}
\hline \multirow[b]{2}{*}{ MRS } & \multicolumn{2}{|c|}{ Histopathology } & \multirow[b]{2}{*}{$\begin{array}{c}P \\
\text { value }\end{array}$} \\
\hline & $\begin{array}{c}\text { Focal Liver } \\
\text { Malignant Lesions } \\
\text { (Positive) }\end{array}$ & $\begin{array}{c}\text { Focal Liver } \\
\text { Malignant Lesions } \\
\text { (Negative) }\end{array}$ & \\
\hline Positive & $\begin{array}{l}\text { True positive(a) } \\
40\end{array}$ & $\begin{array}{l}\text { False positive (b) } \\
4\end{array}$ & \multirow{2}{*}{0.000} \\
\hline Negative & $\begin{array}{c}\text { False negative }(c) \\
3\end{array}$ & $\begin{array}{l}\text { True negative (d) } \\
40\end{array}$ & \\
\hline
\end{tabular}

Sensitivity $\quad=a /(a+c) \times 100=93.02 \%$

Specificity $\quad=d /(d+b) \times 100=90.91 \%$

Positive predictive value $=a /(a+b) \times 100=90.91 \%$

Negative predictive value $=d /(d+c) \times 100=93.02 \%$

Accuracy rate $=a+d /(a+d+b+c) \times 100=91.95 \%$

Positive Likelihood Ratio: 10.23

Negative Likelihood Ratio: 0.08

Table 5: Diagnostic accuracy of MR-Spectroscopy in diagnosis of focal liver malignant lesions taking histopathology as gold standard with regards to gender

Gender: Male

\begin{tabular}{|c|c|c|c|}
\hline \multirow[b]{2}{*}{ MRS } & \multicolumn{2}{|c|}{ Histopathology } & \multirow[b]{2}{*}{$\begin{array}{c}P \\
\text { value }\end{array}$} \\
\hline & $\begin{array}{c}\text { Focal Liver } \\
\text { Malignant Lesions } \\
\text { (Positive) }\end{array}$ & $\begin{array}{c}\text { Focal Liver } \\
\text { Malignant Lesions } \\
\text { (Negative) }\end{array}$ & \\
\hline Positive & $\begin{array}{c}\text { True positive(a) } \\
20\end{array}$ & $\begin{array}{c}\text { False positive (b) } \\
0\end{array}$ & \multirow{2}{*}{0.000} \\
\hline Negative & $\begin{array}{l}\text { False negative(c) } \\
4\end{array}$ & $\begin{array}{l}\text { True negative (d) } \\
26\end{array}$ & \\
\hline
\end{tabular}

Sensitivity $\quad=a /(a+c) \times 100=83.33 \%$

Specificity $\quad=d /(d+b) \times 100=100.00 \%$

Positive predictive value $=a /(a+b) \times 100=100 \%$

Negative predictive value $=d /(d+c) \times 100=86.67 \%$

Accuracy rate $=a+d /(a+d+b+c) \times 100=92.00 \%$

Negative Likelihood Ratio: 0.17

Gender: Female

\begin{tabular}{|c|c|c|c|}
\hline \multirow[b]{2}{*}{ MRS } & \multicolumn{2}{|c|}{ Histopathology } & \multirow[b]{2}{*}{$\begin{array}{c}P \\
\text { value }\end{array}$} \\
\hline & $\begin{array}{c}\text { Focal Liver } \\
\text { Malignant Lesions } \\
\text { (Positive) } \\
\end{array}$ & $\begin{array}{c}\text { Focal Liver } \\
\text { Malignant Lesions } \\
\text { (Negative) }\end{array}$ & \\
\hline Positive & $\begin{array}{l}\text { True positive(a) } \\
28\end{array}$ & $\begin{array}{l}\text { False positive (b) } \\
5\end{array}$ & \multirow{2}{*}{0.000} \\
\hline Negative & $\begin{array}{c}\text { False negative(c) } \\
0\end{array}$ & $\begin{array}{l}\text { True negative }(\mathrm{d}) \\
20\end{array}$ & \\
\hline $\begin{array}{l}\text { Sensitıvity } \\
\text { Specificity } \\
\text { Positive pr } \\
\text { Negative p } \\
\text { Accuracy r } \\
\text { Positive Lik } \\
\text { Negative L }\end{array}$ & 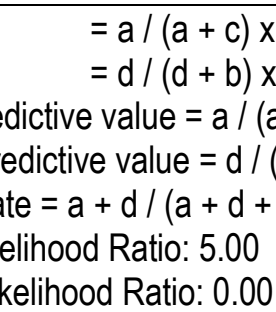 & $\begin{array}{l}00=100 \% \\
00=80.00 \% \\
\text { b) } \times 100=84.85 \% \\
+ \text { c) } \times 100=100 \% \\
+ \text { c) } \times 100=90.57 \%\end{array}$ & \\
\hline
\end{tabular}




\section{DISCUSSION}

The liver is a particularly suitable and interesting organ for metabolic studies as it plays a central role in intermediary metabolism, has a high metabolic activity with rapid response to metabolic insults, and is profoundly altered in acute and chronic diseases. Magnetic resonance spectroscopy (MRS) has been established as a non-invasive technique to study cellular biochemistry and metabolism, both at high magnetic strengths in vitro and in the whole body in vivo at field strengths.

In this study, out of 115 cases, $24.35 \%(n=28)$ were between 15 40 years of age whereas $75.65 \%(n=87)$ were between $41-65$ years of age, mean $\pm S D$ was calculated as $36.77 \pm 12.98$ years, $53.91 \%(n=62)$ were male and $46.09 \%(n=53)$ were females. Frequency of focal liver malignant lesions on histopathology as gold standard was calculated as $55.65 \%(n=64)$ whereas $44.35 \%$ ( $n=51)$. Diagnostic accuracy of MR-spectroscopy in diagnosis of focal liver malignant lesions taking histopathology as gold standard was calculated as $93.75 \%$ for sensitivity, $90.20 \%$ for specificity, $92.31 \%$ for positive predictive value, $92.00 \%$ for negative predictive value and $92.17 \%$ for accuracy rate, positive likelihood ratio was 9.56 and negative likelihood ratio was 0.07 .

The findings of this study are in agreement with a study where the sensitivity of MRS in differentiating cirrhotic liver tissue and $\mathrm{HCC}$ is $95.8 \%$ and specificity is $88.9 \%$ keeping histopathology as gold standard which shows high specificity $(98-100 \%)$ and high sensitivity (86-100\%) for the diagnosis of malignancy. ${ }^{1}$

EGW ter Voert and others ${ }^{1}$ are of the view that Magnetic resonance (MR) is commonly used to identify anatomical lesions, but it is a very versatile technique and also can provide specific information on tumor pathophysiology and metabolism, in particular with the application of MR spectroscopy (MRS). This may include data on the type, grade and stage of tumors, and thus assist in further management of the disease.

Soper et a ${ }^{\Gamma}$ performed a diagnostic correlation between MR spectra and histopathology. They analyzed liver tissue specimens from 54 patients undergoing partial or total hepatectomy. The samples included 31 normal, 59 cirrhotic and 32 hepatocellular carcinoma (HCC) histologically confirmed tissues and were analyzed by H MRS at 8.5 Tesla. ${ }^{1}$ They found reduced amounts of lipids and carbohydrate residues and increased tCho in HCC compared to all normal and all cirrhotic liver tissue. Cirrhotic liver tissue and HCC were distinguished with a sensitivity and specificity of $95.8 \%$ and $88.9 \%$, respectively. Lactate signals of variable intensity were found at $1.3 \mathrm{ppm}$, probably resulting from anaerobic metabolism after excision.

Kuo et $a^{8}$ investigated the value of in vivo $\mathrm{HMRS}^{1}$ in the assessment of large focal hepatic lesions. They included 43 consecutive patients and 8 normal volunteers in a prospective MRS study. MRS was performed at 3.0T with shallow and regular breathing. Single voxel PRESS with TE $=30 \mathrm{~ms}, \mathrm{TR}=$ $1500 \mathrm{~ms}, 256$ averages, was used to select a volume of $2 \mathrm{~cm} \times$ $2 \mathrm{~cm} \times 3 \mathrm{~cm}$. The voxel of interest was located in the largest solid portion of hepatic tumors in patients. Healthy liver data was collected from an area at the centre of the right hepatic lobe for normal volunteers, or in an uninvolved area of the right hepatic lobe in patients. Patients with diffuse-type HCC, with focal nodular hyperplasia and obvious fatty infiltration, and histological unconfirmed lesions were excluded. Thirty-three lesions (21 HCC, 2 angiosarcomas, 1 lymphoma and 9 hemangiomas) were included. They found that malignant tumors had elevated tCho resonances compared to uninvolved liver or benign tumors, but the difference in mean tCho/lipid ratio between malignant tumors or uninvolved liver did not reach statistical significance. Several factors may have contributed to these results.

Local studies are lacking in this regard; however, our findings are guide and helpful for the physician and oncologist in their treatment plans and will avoid the patients fear and complications of interventional procedure. Furthermore, as we used histopathology as gold standard so by providing accurate characterization of the histologic subtype of liver lesion using a non-invasive method, it is helpful for concerned doctor in their management strategy towards patient.

\section{CONCLUSION}

It is concluded that the diagnostic accuracy of MR-spectroscopy is higher in diagnosing of focal liver malignant lesions taking histopathology as gold standard. However, these findings are primary and needs validation through some other local studies.

\section{LIMITATIONS}

As MR spectroscopy is used for benign and malignant liver lesions, nodal and metastatic spread in chest, abdomen and skeleton could not be included in the study.

\section{SUGGESTIONS / RECOMMENDATIONS}

For diffuse liver disease, benign and malignant liver lesions, to monitor tumor response to therapy.

\section{CONFLICT OF INTEREST / DISCLOSURE} None.

\section{ACKNOWLEDGEMENTS}

Help qualitative diagnosis of lesions when pure routine imaging modalities are insufficient to make diagnosis. Assess tumor range and puncture location. Assess clinical of tumor treatments and tumor residual/recurrence.

\section{REFERENCES}

1. TerVoert EGW, Heijmen L, van Laarhoven HW, Heerschap A. In vivo magnetic resonance spectroscopy of liver tumors and metastasis. World J Gastroenterol 2011;17:5133-49.

2. Marrero JA, Ahn J, Reddy KR. ACG clinical guideline: the diagnosis and management of focal liver lesions. Am J Gastroenterol. 2014;109:1328-47.

3. Wang D, Li Y. 1H magnetic resonance spectroscopy predicts hepatocellular carcinoma with liver cirrhosis : a randomized trial . Medicine(Baltimore). 2015;94:e1066.

4. Shen ZW, Cao Z, You KZ, Yang ZX, Xiao YY, Cheng XF. Quantification of choline concentration following liver cell 
apoptosis using $1 \mathrm{H}$ magnetic resonance spectroscopy: World $\mathrm{J}$ Gastroenterology. 2012;18:1130-6.

5. Cheung JS, Fan SJ, Gao DS, Chow AM, Yang J, Man K. In vivo lipid profiling using proton magnetic resonance spectroscopy in an experimental liver fibrosis model. Acad Radiol. 2011;18:37783.

6. Tang ZY, Zhao JN, Zhong WJ, Luo YD, WuW, Chen WJ. The value of proton magnetic resonance spectroscopy in highintensity focused ultrasound treatment of experimental liver cancer. Trans Oncol. 2015;8:163-8.
7. Soper R, Himmelreich U, Painter D, Somorjai RL, Lean CL, Dolenko B, Mountford CE, Russell P. Pathology of hepatocellular carcinoma and its precursors using proton magnetic resonance spectroscopy and a statistical classification strategy. Pathology 2002;34:417-22

8. Kuo YT, Li CW, Chen CY, Jao J, Wu DK, Liu GC. In vivo proton magnetic resonance spectroscopy of large focal hepatic lesions and metabolite change of hepatocellular carcinoma before and after transcatheter arterial chemoembolization using 3.0-T MR scanner. J Magn Reson Imaging 2004;19: 598-604.

\section{AUTHORSHIP AND CONTRIBUTION DECLARATION}

\begin{tabular}{|c|c|c|}
\hline AUTHORS & Contribution to The Paper & Signatures \\
\hline $\begin{array}{l}\text { Dr. Nosheen Ahmad } \\
\text { Assistant Professor, Radiology } \\
\text { FMU / Allied Hospital, Faisalabad Pakistan }\end{array}$ & Data Collection & nother \\
\hline $\begin{array}{l}\text { Dr. Sehrish Israr } \\
\text { Women Medical Officer, Radiology } \\
\text { Allied Hospital, Faisalabad Pakistan }\end{array}$ & Manuscript Writing & 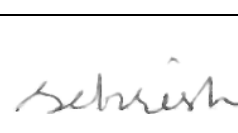 \\
\hline $\begin{array}{l}\text { Dr. Sumaira Irshad } \\
\text { Women Medical Officer, Radiology } \\
\text { Allied Hospital, Faisalabad Pakistan }\end{array}$ & Literature Review & \\
\hline $\begin{array}{l}\text { Dr. Irfan Shabbir } \\
\text { Senior Registrar, Radiology } \\
\text { Allied Hospital, Faisalabad Pakistan }\end{array}$ & Comparison of Results & \\
\hline $\begin{array}{l}\text { Dr. Amna Rehan } \\
\text { Assistant Professor, Radiology } \\
\text { FMU / Allied Hospital, Faisalabad Pakistan }\end{array}$ & References Collection & \\
\hline $\begin{array}{l}\text { Dr. Hassan Bukhari } \\
\text { Assistant Professor, Radiology } \\
\text { FMU / Allied Hospital, Faisalabad Pakistan }\end{array}$ & Data \& Statistical Analysis & \\
\hline
\end{tabular}

